\title{
Desafios e dificuldades do financiamento em saúde bucal: uma análise qualitativa*
}

\author{
Suzely Adas Saliba Moimaz** \\ Cléa Adas Saliba Garbin*** \\ Artênio José Ísper Garbin**** \\ Nelly Foster Ferreira***** \\ Patrícia Elaine Gonçalves******
}

Sumário: 1. Introdução; 2. Metodologia; 3. Resultados e discussão; 4. Conclusão.

Summary: 1. Introduction; 2. Methodology; 3. Results and discussion; 4. Conclusion.

Palavras-chave: financiamento; saúde pública; saúde bucal.

KEY wORDs: financing; public health; oral health.

Os princípios de universalidade, integralidade e eqüidade do SUS só podem ser viabilizados com a construção de um modelo de financiamento flexível e transparente que permita o controle social e ofereça a agilidade no uso dos recursos. Este artigo analisa as dificuldades e desafios do financiamento da saúde bucal na ótica de gestores e técnicos da área. A coleta de dados ocorreu por meio de entrevistas, que

\footnotetext{
* Artigo recebido em dez. 2007 e aceito em jun. 2008.

** Professora do Programa de Pós-Graduação em Odontologia Preventiva e Social e professora adjunta do Departamento de Odontologia Infantil e Social da Faculdade de Odontologia de Araçatuba - Unesp. Endereço: Rua José Bonifácio, 1193, Caixa Postal 341 - Araçatuba — CEP 16015-050, São Paulo, SP, Brasil. E-mail: sasaliba@foa.unesp.br.

*** Coordenadora do Programa de Pós-Graduação em Odontologia Preventiva e Social e professora adjunta do Departamento de Odontologia Infantil e Social da Faculdade de Odontologia de Araçatuba - Unesp.

**** Professor do Programa de Pós-Graduação em Odontologia Preventiva e Social e professor doutor do Departamento de Odontologia Infantil e Social da Faculdade de Odontologia de Araçatuba - Unesp.

$* * * * *$ Doutoranda do Programa de Pós-Graduação em Odontologia Preventiva e Social da Faculdade de Odontologia de Araçatuba - Unesp.

******* Doutoranda do Programa de Pós-Graduação em Odontologia Preventiva e Social da Faculdade de Odontologia de Araçatuba - Unesp.
} 
foram gravadas e transcritas para análise qualitativa, preconizada por Bardin. As dificuldades relatadas pelos entrevistados foram expressas em frases como: "Procuro cumprir a agenda, porém muita coisa não consegui devido à falta de recursos", "não se sabe o quanto pode gastar", "escassez de recursos para procedimentos de média e grande complexidades", "falta de recurso para troca de equipamento" e "prioridade para compra de materiais". No que tange aos desafios foi relatada a necessidade de "capacitação", "formação" e "organização" dos recursos humanos em saúde pública. Observa-se a dificuldade na realização completa do plano previsto de gestão, assim como a necessidade de compromisso por parte dos gestores em acompanhar as etapas de todo processo de repasse financeiro e aplicação do mesmo.

\section{Challenges and difficulties of financing oral health: a qualitative analysis}

The principles of universality, completeness, and equity of the Unified Health System (SUS) only can be made viable with the construction of a flexible and transparent financing model that allows social control and offers agility in the use of resources. This article analyzes the difficulties and challenges of oral health financing in the perspective of managers and technicians who work in the Unique Health System. Data was collected through interviews, which were recorded and transcribed for qualitative analysis, according to Bardin's method. The difficulties reported by all interviewees were expressed by phrases such as "I try to fulfill my commitments, but I don't succeed due the lack of resources", "I don't know how much money I can spend", "scarce resources for medium and high complexity procedures", "lack of resources for replacing equipments" and "priority for purchasing materials". While discussing the challenges, the interviewees emphasized the need for "qualification", "training" and "planning" of human resources in public health. They also mentioned the difficulty in accomplishing the management plan, as in obtaining the managers' commitment in following all the stages of the transfer and application of funds.

\section{Introdução}

A oferta de bens e serviços de saúde é uma das mais complexas e árduas tarefas no mundo moderno. Por outro lado, há evidentes limitações da capacidade de produzir tais bens e serviços na proporção da demanda, em virtude de diversos fatores. Muitas limitações são aceitas, como as barreiras tecnológicas ou a falta dos recursos financeiros (Santana, 1997).

O modelo de financiamento da saúde do Brasil combina origens de recursos públicos e privados, mas estes ainda contam com as subvenções diretas e indiretas do Estado, ou seja, as ações e serviços de saúde implementados pelos estados, municípios e Distrito Federal são financiados com recursos da União, próprios e de outras fontes suplementares de financiamento como: recursos das contribuições sociais dos empregados sobre a fo- 
lha de pagamento, dos patrões sobre a folha, sobre o faturamento e sobre o lucro; e por parte dos recursos dos concursos prognósticos (loto, sena, supersena etc.) todos devidamente contemplados no orçamento da seguridade social. Esses recursos são repassados por meio de transferências regulares e automáticas, remuneração por serviços produzidos, convênios, contratos de repasses e instrumentos similares (Andrade, 2005; Brasil, 2003; Brasil, 2005; Cohn e Elias, 1999; Correia, 2000). É fundamental reconhecer que os recursos financeiros destinados às ações e serviços de saúde podem ser otimizados com um planejamento voltado para o atendimento das necessidades de saúde da população.

O objetivo deste artigo foi realizar uma análise qualitativa e oferecer um panorama dos desafios e dificuldades do financiamento do sistema de saúde brasileiro em saúde bucal enfrentado por técnico da esfera estadual e por três gestores municipais de saúde bucal do Departamento Regional de Saúde DRS-II.

\section{Metodologia}

O trabalho foi submetido e aprovado pelo Comitê de Ética em Pesquisa da Faculdade de Odontologia de Araçatuba, seguindo as diretrizes éticas da Resolução no 196/96, promulgada pelo Conselho Nacional de Saúde, protocolado sob o no 2005-00749.

Participaram desta pesquisa: um técnico da esfera estadual e três gestores municipais de saúde de três municípios, pertencentes à DRS-II, região noroeste do estado de São Paulo, escolhidos aleatoriamente. Os mesmos deram sua anuência para participar da pesquisa por meio da assinatura do termo de consentimento livre e esclarecido. A coleta de dados ocorreu por meio de entrevistas semi-estruturadas, que foram gravadas e transcritas na íntegra. As questões contemplaram temas relativos ao financiamento de serviços, especialmente repasses das esferas federal e estadual, elaboração, planejamento e prioridades para aplicação dos recursos, participação popular, aplicação dos recursos para saúde e saúde bucal, dificuldades e os desafios durante a gestão.

Inicialmente as transcrições foram lidas e analisadas na íntegra. Num segundo momento, releituras foram realizadas e identificadas em categorias qualitativamente, quanto ao seu conteúdo, a partir da análise de conteúdo temática preconizada por Bardin. A mesma define as categorias como rubricas ou classes, que reúnem um grupo sob um título genérico. 


\section{Resultados e discussão}

A análise das respostas ocorreu separadamente para cada questão, devido à especificidade de cada uma, como vemos a seguir.

\section{0 repasse financeiro}

As descrições enfatizam a origem e os modelos de repasse financeiro.

Segundo técnico da esfera estadual:

O repasse financeiro é diretamente do Ministério da Saúde pro próprio município, no Fundo Municipal de Saúde por número de habitantes (...) O que é chamado $\mathrm{PAB}$, piso de atenção básica. $\mathrm{E}$ os atendimentos especializados que são dinheiro à parte pra alguns programas, por exemplo: saúde da família, e o saúde bucal no PSF, e alguns outros incentivos que são pagos separadamente.

De acordo com gestores municipais:

Das entradas de verbas próprias que o município tem que gastar obrigatoriamente até $15 \%$, (...) e temos as verbas casadas, que são as dos programas que vêm diretamente do Ministério, e essa gerenciada já pelo fundo, com a participação do Conselho Municipal e do Gestor. Tem repasse é (...) federal, do estado e município.

Os dados mencionados especificam que o repasse financeiro se dá por meio de transferências fundo a fundo de saúde, e demonstram que esses gestores têm conhecimento de como são repassadas as verbas para a saúde. Os fundos de saúde foram promulgados pela Lei Orgânica da Saúde (Lei n ${ }^{\mathrm{o}}$ 8.080/90) em seu art. 33, que define que os recursos financeiros do SUS serão depositados em conta especial, em cada esfera de atuação, e movimentados sob a fiscalização dos respectivos conselhos de saúde, especificada como fundo de saúde pela Lei no ${ }^{\circ}$.142/90; e tornou-se mais clara com a edição da EC no 29/2000, que define que a utilização dos recursos para a saúde somente poderá ser feita por meio dos conselhos (Brasil, 2003).

Assim, os recursos destinados à execução da atenção básica e das ações específicas de programas e incentivos do Ministério da Saúde são transferidos do Fundo Nacional de Saúde para os fundos estaduais ou municipais de saúde, observadas as condições de gestão, bem como as qualificações de estados e 
municípios aos respectivos programas e incentivos, de acordo com a regulamentação específica (Brasil, 2003). Malamed e Costa (2003) relatam que as transferências para os municípios cresceram de $24,1 \%$ do total de recursos disponibilizados pelo Ministério da Saúde em 1997 para 66,90\% em 2001.

O PAB (piso de atenção básica) consiste nos recursos financeiros destinados, exclusivamente, ao financiamento das ações de atenção básica à saúde. Ele é composto de uma parte fixa de recursos (PAB-fixo) destinados à assistência básica e de uma parte variável (PAB-variável), relativa a incentivos para o desenvolvimento dos programas executados nesse nível de atenção. Os recursos correspondentes à parte fixa são obtidos pela multiplicação de um valor per capita nacional pela população de cada município e são transferidos direta e automaticamente do Fundo Nacional de Saúde para os fundos municipais correspondentes. Porém, na realidade, o valor dessa transferência per capita varia de $R \$ 10$ a $R \$ 18$. A implantação do PAB traz como principal mecanismo a transferência regular e automática, o que se traduz em um repasse federal feito diretamente aos municípios, o que dissocia a produção do faturamento, característica central do sistema de financiamento anterior. Isto é, de acordo com a lógica de pagamento por serviços previamente prestados, os municípios mais pobres e/ou de menor porte, sem uma infra-estrutura adequada de unidades e de estabelecimentos de saúde, acabavam prejudicados (Brasil, 2003; Malamed e Costa, 2003).

\section{Gastos na saúde}

Os entrevistados expressam as percentagens aplicadas e ressaltam a responsabilidade desses gastos.

De acordo com técnico da esfera estadual: "Até 2004 era para aplicar pelo menos $15 \%$ na saúde, mas tem municípios que aplicam até mais de 15\%".

Segundo os gestores municipais: "O município investe em saúde em torno de 25\%"; "Pela responsabilidade fiscal, você sabe que tem a questão do mínimo $15 \%$ (...), mas é gerenciamento de empresa mesmo, senão acumula, (...) você vai preso, e vai mesmo".

Para os estados, o Distrito Federal e os municípios, no ano de 2000 foi estabelecida a obrigatoriedade de aplicação de um percentual mínimo de 7\% da receita de impostos, inclusive as transferências constitucionais e legais. Nos exercícios seguintes, esse percentual deveria ser acrescido anualmente, à razão de $1 / 5$, até atingir, em 2004, o percentual mínimo de $12 \%$ para as receitas estaduais e de $15 \%$ para as receitas municipais, e aqueles que não cumprirem 
os limites mínimos estabelecidos pela Constituição Federal estarão sujeitos às mesmas sanções da Lei de Responsabilidade Fiscal (LRF), que vão desde a retenção das transferências do Fundo de Participação dos Estados (FPE) e dos municípios (FPM), até a intervenção da União no estado, no Distrito Federal e nos municípios e/ou da União, ou dos estados nos municípios, bem como a cassação de mandatos (Brasil, 2003). O criterioso acompanhamento da aplicação dos recursos vinculados é compromisso ético e profissional com a construção do SUS (Teixeira e Teixeira, 2003).

Faveret (2002), em sua pesquisa realizada a partir de dados do Sistema de Informações sobre Orçamentos Públicos em Saúde (Siops) e da Secretaria Executiva, ambos do Ministério da Saúde, observou que os recursos destinados aos serviços públicos de saúde somaram em 2000 cerca de $\mathrm{R} \$ 37$ bilhões, sendo que $22,7 \%$ deste valor foi contribuído pelos municípios.

\section{O investimento na saúde bucal}

Os relatos demonstram a dificuldade de uma verba específica para saúde bucal. De acordo com técnico da esfera estadual:

Na saúde bucal não existe uma porcentagem específica da parte de saúde. A maioria das discussões, (...) Congresso (...) e até na Conferência Nacional de Saúde, foi discutido, justamente isso: ter um repasse já fixo pra saúde bucal. Porque o coordenador de Saúde Bucal, muitas vezes, nem fica sabendo se realmente o dinheiro está sendo aplicado na saúde bucal, mesmo os próprios incentivos que chegam pro programa saúde da família.

Segundo os gestores municipais:

vem um montante para saúde, daí então, eles não dividem. Um tanto é pra saúde bucal (...) eles vão trabalhando (...) conforme os pedidos vão sendo feitos pro departamento de compras (...) dependendo se tem ou não dotação eles vão encaminhando os pedidos. Pra saúde bucal este ano, nós gastamos em materiais (medicamentos, material de consumo e algum material permanente), sem recursos humanos, em torno de $\mathrm{R} \$ 60$ mil e parte desse dinheiro foi de $\mathrm{R} \$ 24$ mil do PSF, que nós implantamos quatro equipes.

Confrontando a resposta do técnico da esfera estadual, com as dos gestores municipais, observa-se que não existe uma percentagem específica des- 
tinada à saúde bucal, oriunda do repasse ao Fundo de Saúde Municipal, bem como para outras subáreas ou ações da saúde. Portanto, os incentivos financeiros, que se dão mediante a implantação de equipe de saúde bucal (ESB), no Programa Saúde da Família (PSF), o primeiro no valor de R $\$ 6$ mil em uma única parcela a cada ESB implantada, e também por meio da modalidade da ESB (modalidade tipo I - um cirurgião-dentista e um atendente de consultório dentário - R $\$ 20.400 /$ ano por equipe implantada, e modalidade tipo II - um cirurgião-dentista; um atendente de consultório dentário e um técnico de higiene dental $-\mathrm{R} \$ 26.400 /$ ano por equipe implantada), tornam-se os únicos investimentos específicos na saúde bucal. Deve-se ressaltar que o incentivo financeiro de R $\$ 6$ mil é destinado apenas para implantação da equipe, ou seja, esse investimento não se repetirá posteriormente e com isso a saúde bucal retorna à situação de não possuir um investimento específico (Costa, Chagas e Silvestre, 2006).

Marques e Mendes (2002) relatam que essas regras de distribuição dos incentivos, do governo federal e/ou dos governos estaduais, induziram à implantação de centenas de novas equipes municipais, muitas vezes sem a menor possibilidade de serem mantidas sem esses repasses. Para se ter uma idéia desse crescimento, segundo o Ministério da Saúde, o número de equipes de saúde da família aumentou de 328, em 1994, para cerca de 24.562 em dezembro de 2005 (Costa, Chagas e Silvestre, 2006).

\section{A elaboração do Plano Plurianual (PPA), agenda de saúde e plano de saúde}

Observa-se a importância da elaboração desses instrumentos para o planejamento e avaliação da aplicação dos recursos financeiros.

Segundo os gestores municipais:

Nós fizemos o plano em 2003. Nós estamos administrando as verbas do fundo esse ano, 2004, porque na verdade essa verba era gerenciada pela própria prefeitura (...) agora como realmente assumiu essa questão de Secretaria (...) agora a verba vem diretamente pro fundo da Secretaria.

Todo ano nós sentamos e reavaliamos esse plano. Em 2001 você senta, vai ver todos os projetos dos programas realizados durante esses 4 anos, e agora em 2004, nós sentamos pra ver o que nós executamos dentro dos planejados e o que não poderíamos executar. 
O discurso apresentado mostra que o gestor tem a consciência da construção dos instrumentos de gestão financeira do SUS que integre as funções planejar, orçar, executar, acompanhar, fiscalizar e avaliar os recursos aplicados em saúde, com sistemas de informação orientados para a sua transparência, expresso em leis e atos normativos, que garantam o compromisso dos mesmos com a manutenção de fontes estáveis, e que possibilitem o controle social sobre todas as etapas como é demonstrado a seguir: planejamento (agenda de saúde, plano de saúde, Plano Plurianual — PPA, Lei de Diretrizes Orçamentárias - LDO); orçamento (LOA — Lei Orçamentária Anual compatível com o planejamento); execução orçamentária e financeira (fundo de saúde); acompanhamento e fiscalização (relatório de gestão, Conselho de Saúde, controle social) (Brasil, 2003, 2004).

O repasse financiamento dar-se-á mediante a elaboração do Plano Plurianual (PPA) e agenda de saúde. O PPA é elaborado no primeiro ano de mandato do governante e encaminhado para a aprovação do Poder Legislativo até 31 de agosto, para viger nos $2^{\circ}, 3^{\circ}$ e $4^{\circ}$ anos do seu mandato, e no $1^{\circ}$ do mandato do seu sucessor. O PPA contém as metas de governo e toma por base a agenda de saúde e as metas plurianuais contidas nos planos de saúde. É com base no PPA que é elaborada a Lei de Diretrizes Orçamentárias (LDO), contendo as orientações para a preparação do orçamento (Brasil, 2003). Porém, observa-se nas respostas dos gestores municipais que a elaboração do PPA, agenda de saúde e plano de saúde ocorreu no primeiro e terceiro anos de gestão, o que não coincide com as normas regulamentadas para esse fim, mas é justificável devido ao fato de essa regulamentação estar em vigor a partir de 2000.

\section{A participação do Conselho de Saúde}

As descrições enfatizam a atuação e a importância da participação do Conselho de Saúde na aplicação de recursos financeiros.

Segundo o relato dos gestores municipais:

O conselho é muito forte. Tudo discutido. Fizemos a Conferência Municipal de Saúde no ano passado. A partir da conferência nós traçamos os planos diretores e tal. O conselho é muito atuante, a participação da comunidade, tal (...)

Nós temos no conselho 12 titulares e 12 suplentes (...) vai numa média de freqüência nesse conselho de pelo menos umas 15 pessoas. Eles participaram desse plano, são totalmente ativos. 
O discurso demonstra a concreta efetivação de forma positiva de um dos princípios do SUS, o controle social. A Emenda Constitucional no 29/2000 diz que os recursos depositados nos fundos de saúde devem ser acompanhados e fiscalizados pelos conselhos de Saúde. A atividade de acompanhamento deve ser exercida por quem tem essa competência, de forma proativa, ou seja, em obediência a uma ação planejada que visa orientar a execução de forma correta e coibir os atos de má gestão (Brasil, 2003).

Hoje os espaços políticos de representação definidos para usuários, profissionais e dirigentes de unidades de saúde, que certamente detêm uma parcela importante de informação e da inteligência sobre a dinâmica de funcionamento dos serviços de saúde, estão restritos à participação nos conselhos de Saúde (Santos e Gerschman, 2004). Cortes (1998) e Gerschman (2003) consideram que só há participação dos conselhos na medida em que se cria a possibilidade de tomar parte no processo de decisão política, e o papel político dos conselhos muitas vezes não é identificado no discurso de conselheiros representantes de usuários, que é pautado pela descrença de que de fato possam contribuir para a saúde da população.

\section{A prioridade de aplicação da verba em saúde bucal}

Os relatos apontam que a aplicação de recursos na saúde bucal é voltada à prevenção e compra de materiais.

De acordo com técnico da esfera estadual:

A verba de saúde bucal é gasta em material. As verbas específicas dos programas da saúde da família são verbas engessadas, têm que ser gastas com materiais. A área odontológica não dá prejuízo, porque principalmente são procedimentos coletivos, e eles são muito bem pagos pro município e, é prevenção. E prevenção não se gasta com ela.

Já segundo os gestores municipais: "a prioridade foi mesmo atender a população, da parte de prevenção, curativo"; "a prioridade básica é a compra de material de consumo".

Teixeira e Teixeira (2003) concordam com as respostas dos participantes no que tange à mobilização de recursos financeiros para a obtenção de materiais e investimentos em infra-estrutura, que são indispensáveis à efetiva ação sanitária. Assegurar um fluxo adequado, contínuo e permanente de recursos financeiros ao provimento das referidas ações constitui pre- 
condição para a resolução de inúmeros problemas de saúde da população brasileira.

Segundo o Manual do SUS (2003), os gastos com o atendimento das necessidades da área de saúde pública devem observar as diretrizes e princípios do SUS e ser destinados às ações e serviços de acesso universal, igualitário e gratuito, além de estar em conformidade com objetivos e metas explicitados nos respectivos planos de saúde. Parece elementar, porém é necessário atentar, no âmbito de cada nível de gestão do SUS, para aquilo que concorre efetiva e diretamente na promoção, proteção, recuperação e reabilitação da saúde. Para efeito de cumprimento dos limites constitucionais, as despesas com saúde não devem ser confundidas com as relacionadas a outras políticas públicas que atuam sobre determinantes sociais e econômicos, ainda que incidentes sobre as condições de saúde.

Nota-se nas respostas que, há 13 anos, desde que a saúde no país foi instituída como um direito de todos e um dever do Estado e operada por meio do Sistema Único de Saúde (SUS), que os gestores desse sistema vêm atribuindo ênfase à mudança do modelo de atenção à saúde, priorizando o nível de atenção básica conforme observado também por Marques e Mendes (2002). Nesse período de existência do SUS, vários modelos assistenciais foram implementados nas diversas localidades, tais como: a "vigilância em saúde", "ações programáticas de saúde", "saúde da família" etc.

\section{As dificuldades}

Os relatos enfatizam a escassez de recursos financeiros.

Segundo técnico da esfera estadual:

O coordenador de saúde bucal não tem conhecimento de quanto passa para a área odontológica, fica mais difícil de ele cobrar do gestor. E se ele não tiver conhecimento de como é que é tudo isso, como é o funcionamento do SUS, mais ainda ele vai ter dificuldade de discutir.

De acordo com os gestores municipais:

Você quer realizar muitas coisas, então sempre falta alguma coisa.

O que eu vejo é o seguinte, pra atenção básica tudo bem (...), mas agora quando o município é incentivado a fazer algumas outras ações de média complexidade, tem que vir a verba. Então é complicado! Igual ao Centro de Especialidades 
Odontológicas - CEO. Quando solicitei o CEO junto ao ministério, porque já temos certas especialidades, precisaria da construção do centro odontológico. Hoje não. Hoje o município constrói, monta e depois vem a verba. Ai é tudo muito complicado.

Em concordância com as respostas obtidas, Teixeira e Teixeira (2003) relatam que a promoção da cidadania de grande parcela da população depende da eficiência do setor público na provisão adequada de ações e serviços de saúde. Esse desafio mostra-se particularmente difícil em um contexto de demanda crescente e restrição orçamentária. Os recursos são escassos, as possibilidades de utilização de subterfúgios de administração financeira, corriqueiros em períodos inflacionários, são limitadas, e por isso é preciso planejar as ações a serem desenvolvidas. Portanto, um planejamento eficaz do gasto e a adequada gestão dos limitados recursos disponíveis são imprescindíveis em todos os setores da economia, em especial no setor público. Pois se observássemos do ponto de vista da ética maior, de inclusão social e sanitária, são milhões de brasileiros sem respostas aos seus problemas de saúde bucal. A mutilação bucal ou falta de acesso a serviços de qualidade é um sintoma da sociedade da exclusão e da barbárie (Moyses, 2004).

Elias, Marques e Mendes (2001) narram que as intenções da NOB/96 eram de separação dos recursos para a média e alta complexidade (MAC) daqueles destinados à atenção básica, mediante a criação do piso da atenção básica (PAB) - fixo ou variável, o que reforçou o papel definidor da política de saúde pela esfera federal. Assim, o aumento de importância das transferências não foi acompanhado pela autonomia dos municípios na determinação da política de saúde. No que abrange procedimentos de média complexidade, os tetos para estados e municípios baseiam-se em média calculada na produção de serviços realizados nos seis meses anteriores.

Malamed e Costa (2003) alertam para uma importante observação sobre as últimas medidas tomadas pelo Ministério da Saúde, pois quando se calcula a média praticada por municípios em todo o país encontram-se resultados muito diferentes, refletindo a diversidade regional. Assim, para que as desigualdades constatadas sejam alteradas parcialmente, sem reduzir o gasto em municípios que apresentam redes mais complexas, buscam-se recursos "novos" para construir um patamar mínimo em todo o território nacional. Porém, observa-se que esse patamar mínimo não cobre os gastos realizados com procedimentos de média complexidade, produzindo gastos para a prefeitura. 


\section{Recursos Humanos}

Os entrevistados apontam falta de capacitação dos recursos humanos e mãode-obra especializada para odontologia.

O técnico da esfera estadual diz:

Pelo que eu vejo, não existe falta de recursos humanos, o que existe é uma falta de organização do trabalho desses recursos humanos. Que se o município tiver um plano de saúde bucal organizado, com uma racionalização desses recursos, daria para trabalhar muito bem com os profissionais já existentes na rede. Eu acho que existe falta de formação, principalmente de gestor, não só de saúde bucal, ou de cargo municipal de saúde, ou até prefeito de não ter conhecimento sobre saúde pública.

Segundo os gestores municipais:

Nossas equipes de saúde bucal são tudo modalidade I, porque nós não temos técnico de higiene bucal (THD). Lógico que a nosso ver, sabemos muito bem que a modalidade II é muito melhor que a modalidade I, só que não tem mãode-obra, infelizmente.

A maioria (das ACDs) não tem formação (...) São poucas que possuem mesmo. E no próprio perfil do dentista também, do próprio profissional (...) Especialista.

Na esteira do governo federal, também as secretarias de estado da Saúde (SES) têm incentivado a implantação do PSF nos últimos anos, uma vez que esse programa é a principal estratégia para o fortalecimento do nível de atenção básica, assumida pelo SUS como sua porta de entrada (Marques e Mendes, 2003).

O incentivo da saúde bucal no PSF pautou a instituição de duas modalidades de equipe de saúde bucal. Foi gerada uma perda de sentido na concepção de equipe única e a operação de expedientes ineqüitativos de financiamento da expansão da oferta. Isso porque o município que opta por implantar equipes na modalidade I (equipe sem THD e repasses anuais menores) só o faz porque suas condições iniciais de oferta são desfavoráveis, dada a impossibilidade imediata local de se trabalhar com THD. Assim, a ausência de THD para a saúde bucal na equipe de saúde da família não se dá porque os municípios não possuem condições iniciais favoráveis (de oferta ou demanda) a ponto de dispensar esse recurso humano auxiliar; mas quase sempre porque os mu- 
nicípios não têm qualquer possibilidade de escolha, dadas as más condições iniciais nas questões de recursos auxiliares (Brasil, 2004). Isso está de acordo com a nossa pesquisa, pois a falta de mão-de-obra de THD foi mencionada e explicitada como fator para a escolha da modalidade I.

\section{Recomendação para mudança no sistema financeiro}

Remetem especificamente a um maior repasse financeiro para a saúde bucal. Segundo técnico da esfera estadual:

O desejo de toda a parte bucal é que tivesse mesmo a porcentagem fixa pra saúde bucal. E melhorar os salários. Porque os salários pro dentista também estão muito baixos, com raras exceções.

O coordenador de saúde bucal teria que ter uma formação primeiro em saúde pública, pra entender melhor tudo o que se passa, porque ele chega muito leigo (...) e até aprender e entender o que é estado, entender o que é o SUS, entender o que é DIR, secretaria do estado e Ministério da Saúde, leva um certo tempo (...).

De acordo com os gestores municipais:

Nós gostaríamos de trocar alguns equipamentos que são caros e já estão antigos então (...) Também reestruturar espaços físicos de algumas unidades e para isso dependemos de verba.

Eu acho que deveria investir mais em saúde bucal (...) é (...) o que repassam para a saúde bucal é muito pouco.

Essas recomendações vêm em parte confirmar o que Santos e Gerschaman (2004) mencionam em seu trabalho, ou seja, os constrangimentos gerados pelo ajuste macroeconômico transformam o Brasil, segundo a Organização Mundial de Saúde, em um dos países com índices mais baixos de investimento público no setor saúde, no continente americano, uma flagrante contradição para um sistema público de caráter universal. O Brasil gastou 8,8\% de seu orçamento com saúde em 2001, ao passo que a Argentina investiu 21,3\% nesse mesmo ano e apenas quatro países caribenhos (Trinidad e Tobago, Santa Lúcia, Belize e Jamaica) dedicaram parcelas ainda menores de seus orçamentos à saúde. 


\section{Conclusão}

Diante do exposto conclui-se que:

v existem dificuldades na realização completa dos planos plurianuais previstos;

v há dificuldade de se estabelecer verba específica para saúde bucal;

v existe demora no repasse e escassez de verba foi relatada pelos gestores;

v há a necessidade de comprometimento, acompanhamento de gestores e técnicos em todas as etapas do processo de repasse e aplicação do recurso financeiro.

\section{Referências bibliográficas}

ANDRADE, L. O. M. Gestão e financiamento do SUS à luz das normas operacionais básicas. Disponível em: <www.saudedafamilia.med.br/publica.SelecaoResidecia. htm>. Acesso em: 6 jun. 2007.

BARDIN, L. Análise de conteúdo. Lisboa: Persona, 1979. 223p.

BRASIL. Gestão financeira do Sistema Único de Saúde: manual básico. Brasília: Ministério da Saúde, Fundo Nacional de Saúde, 2003. 66p.

. Ministério da Saúde. Portaria no 673/GM, de 3 de junho de 2003. Diário Oficial da União, n. 106, seção 1, 4 jun. 2003.

. Ministério da Saúde. Conferência Nacional de Saúde Bucal. 3. Relatório final. Brasília: Ministério da Saúde, 2004. 100p.

. Ministério da Saúde. São Paulo habilitado em gestão plena. Disponível em: < http://portalweb02.saude.gov.br/saude/buscar.cfm>. Acesso em: 2 jun. de 2007.

COHN, A.; ELIAS, P. E. Saúde no Brasil: políticas e organização de serviços. 3. ed. São Paulo: Cortez, 1999. 73p.

CORREIA, M. V. C. Que controle social? Os conselhos de saúde como instrumento. Rio de Janeiro: FioCruz, 2000. 36p.

CORTES, S. M. V. Conselhos municipais de saúde: possibilidades dos usuários participarem e os determinantes da participação. Ciência \& Saúde Coletiva, Rio de Janeiro, v. 3, n. 1, p. 4-37, jan./jun. 1998. 
COSTA, J. F. R.; CHAGAS, L. D.; SILVESTRE, R. M. (Orgs.). A política nacional de saúde bucal do Brasil: registro de uma conquista histórica. Brasília: Organização Pan-Americana da Saúde (Opas), 2006. 67p.

ELIAS, P.; MARQUES, R. M.; MENDES, A. O financiamento e a política de saúde. Revista Universidade de São Paulo, São Paulo, v. 51, n. 1, p. 6-15, jan./mar. 2001.

FAVERET, A. C. Federalismo fiscal e descentralização no Brasil: o financiamento da política de saúde na década de 1990 e início dos anos 2000. 2002. 110 f. Tese (Doutorado em Medicina Social) — Instituto de Medicina Social, Universidade do Estado do Rio de Janeiro, Rio de Janeiro.

GERSCHMAN, S. O setor filantrópico e alguns desafios para as políticas públicas em saúde. Revista de Administração Pública, v. 37, n. 1, p. 265-283, jan./mar. 2003.

MALAMED, C.; COSTA, N. R. Inovações no financiamento federal à atenção básica. Ciência \& Saúde Coletiva , Rio de Janeiro, v. 8, n. 2, p. 393-401, abr./jun. 2003.

MARQUES, R. M.; MENDES, A. A política de incentivos do Ministério da Saúde para atenção básica: uma ameaça à autonomia dos gestores municipais e ao princípio da integralidade? Cadernos de Saúde Pública, Rio de Janeiro, v. 18, p. 163-171, dez. 2002.

; __ Atenção básica e Programa de Saúde da família (PSF): novos rumos para a política de saúde e seu financiamento? Ciência \& Saúde Coletiva, Rio de Janeiro, v. 8, n. 2, p. 403-415, abr./jun. 2003.

MOYSÉS, S. J. Políticas de saúde e formação de recursos humanos em odontologia. Revista da Associação Brasileira de Ensino Odontológico, Brasília, v. 4, n. 1, p. 30-37, jan./jun. 2004.

SANTANA, J. P. (Org.). Desenvolvimento gerencial de unidades básicas do Sistema Único de Saúde (SUS). Brasília: Organização Pan-Americana de Saúde (Opas), 1997. 93p.

SANTOS, M. A. B.; GERSCHMAN, S. As segmentações da oferta de serviços de saúde no Brasil - arranjos institucionais, credores, pagadores e provedores. Ciência \& Saúde Coletiva, Rio de Janeiro, v. 9, n. 3, p. 793-806, jul./set. 2004.

TEIXEIRA, H. V.; TEIXEIRA, M. G. Financiamento da saúde pública no Brasil: a experiência do Siops. Ciência \&. Saúde Coletiva, Rio de Janeiro, v. 8, n. 2, p. 379391, 2003. 